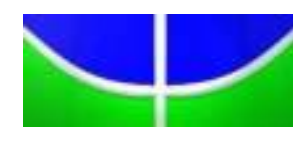

UNIVERSIDADE DE BRASÍLIA

Centro de Excelência em Turismo

Pós-graduação Lato Sensu

Curso de Especialização em Turismo e Desenvolvimento Sustentável

\title{
O IMPACTO CAUSADO PELO FURACÃO KATRINA NA ATIVIDADE TURÍSTICA NO BAIRRO FRANCÊS, NOVA ORLEANS - EUA
}

\author{
Autor: Guilherme Castello Branco Coutinho
}

Orientadora: Doutora lara Lúcia Gomes Brasileiro 


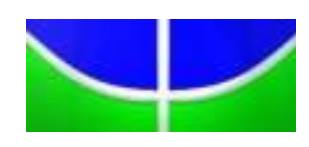

UNIVERSIDADE DE BRASÍLIA

Centro de Excelência em Turismo

Pós-graduação Lato Sensu

Curso de Especialização em Turismo e Desenvolvimento Sustentável

\title{
O IMPACTO CAUSADO PELO FURACÃO KATRINA NA ATIVIDADE TURÍSTICA NO BAIRRO FRANCÊS, NOVA ORLEANS - EUA
}

\author{
Autor: Guilherme Castello Branco Coutinho \\ Orientadora: Doutora lara Lúcia Gomes Brasileiro
}

Monografia apresentada ao Centro de Excelência em Turismo - CET, da Universidade de Brasília - UnB, como requisito parcial à obtenção de grau de Especialista em Turismo e Desenvolvimento Sustentável. 


\section{UNIVERSIDADE DE BRASÍLIA}

Centro de Excelência em Turismo

Pós-graduação Lato Sensu

Curso de Especialização em Turismo e Desenvolvimento Sustentável

Autor: Guilherme Castello Branco Coutinho

Aprovado por:

Professora orientadora: Iara Lúcia Gomes Brasileiro

Professora Dra. Dóris Aleida Villamizar Sayago

Professora MsC Ariadne Pedra Bittencourt

Brasília, 28 de maio de 2007. 


\section{RESUMO}

O objetivo deste trabalho é analisar o impacto que o furacão Katrina causou na atividade turística no Bairro Francês, French Quarter, em Nova Orleans, Estados Unidos da América - EUA. Uma breve explicação do que são fenômenos como esse foi feita e, também, uma elucidação de suas mais comuns conseqüências ao homem e à natureza, não valorizando aspectos irrelevantes de detalhamento à área de estudo do Turismo. Tão importante é sabermos a respeito deste assunto, pois o impacto desse furacão causou vários distúrbios ambientais, emocionais, financeiros, profissionais e sociais não somente na região pesquisada, mas em quase toda a Costa do Golfo americana. Uma análise sintética dos resultados obtidos foi feita a partir do conteúdo apresentado para que, de tal modo, decisões importantes possam ser definidas com relação ao choque na atividade turística causado pelo acontecimento natural. Os futuros planos estratégicos e emergenciais, não somente aqueles referentes à atividade turística, terão como base os dados coletados neste trabalho, minimizando erros e evitando possíveis catástrofes de diversas naturezas caso ocorra novamente um episódio similar. Por fim, considerações finais foram apresentadas para que sirvam como base à elaboração de futuras recomendações para se lidar com o problema, seja no estado atual em que está a situação da região estudada, como nas fases antes, durante e depois de um acontecimento posterior semelhante. É difícil, de fato, obter ilações cientificamente exatas sobre o assunto. Portanto, as conclusões deste artigo são, certamente, um trabalho acadêmico o mais próximo possível da realidade moderna, segundo os indicadores abordados.

Palavras-chave: Meio Ambiente; Sustentabilidade; Turismo 


\begin{abstract}
The objective of this work is to analyze the impact that Hurricane Katrina caused in the tourism activity in the French Quarter, New Orleans, United States of America. A brief explanation of what are phenomena as those was done and, also, a elucidation of its most common consequences to man nature, not valuing irrelevant aspects of detailing to the Tourism's area of study. So important it is to know about this subject, because the impact of this hurricane caused several environmental, emotional, financial, professional and social disturbs not only in the researched region, but in almost all the American Golf Coast. A synthetic analysis of the obtained results was done from the presented content so that, in such way, important decisions can be defined regarding the shock in the tourism activity caused by the natural event. The future strategic and emergency plans, not only those referring to the tourism activity, will have as a base the collected data in this work, minimizing errors and preventing possible catastrophes of diverse natures in case a similar episode occurs again. Finally, final considerations were presented in order to deal with the problem, either in the current state that is the situation of the studied region, as in the phases before, during and after of a similar posterior event. It is difficult, in fact, to obtain scientifically accurate illations on the subject. Therefore, the conclusions of this article are, for certain, an academic work the nearest possible to modern reality, according to the addressed indicators.
\end{abstract}

Keywords: Environment; Sustainability; Tourism 


\title{
LISTA DE ABREVIATURAS E SIGLAS
}

\author{
AIN: Agência Cubana de Noticias \\ EUA: Estados Unidos da América \\ FEMA: Federal Emergency Management Agency \\ NASA: National Aeronautics and Space Administration \\ NBC: National Broadcasting Company \\ NOAA: National Oceanic \& Atmospheric Administration \\ OMM: Organização Mundial de Meteorologia \\ UCLA: University of California, Los Angeles \\ WMO: World Meteorological Organization
}




\section{SUMÁRIO}

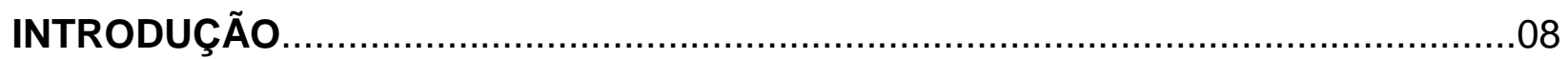

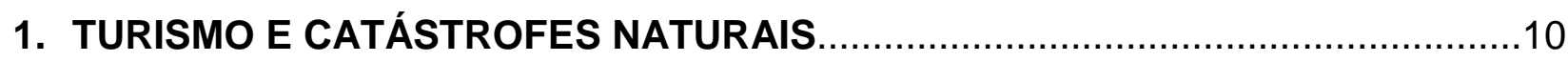

2. DEFINIÇÃO DE UM FURACÃO

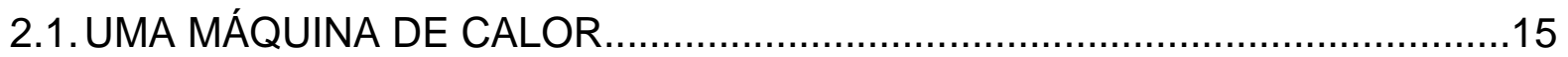

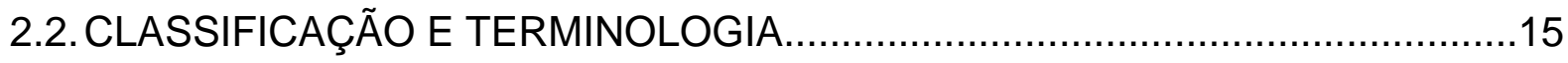

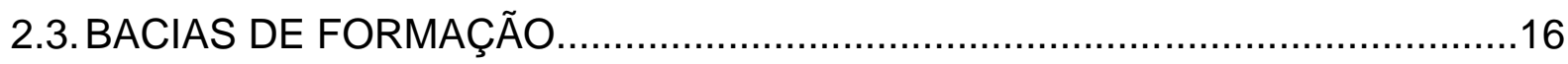

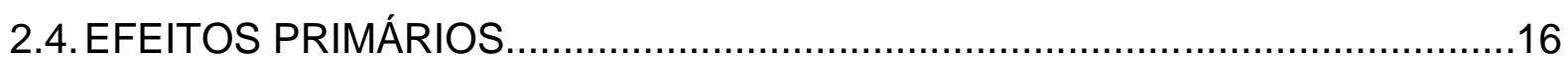

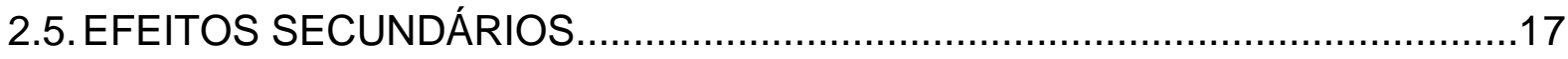

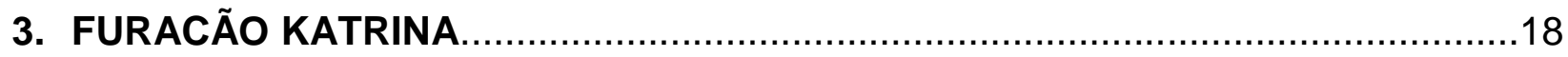

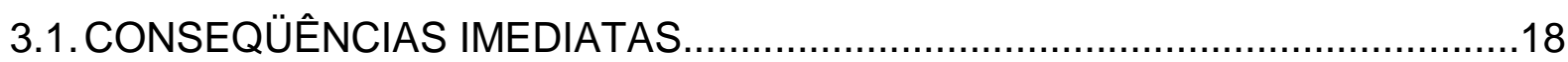

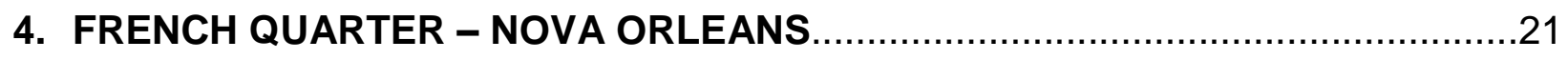

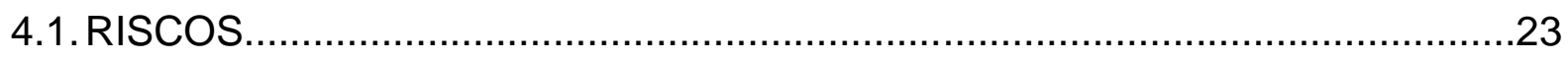

5. IMPACTOS DO FURACÃO KATRINA NO FRENCH QUARTER ...................25

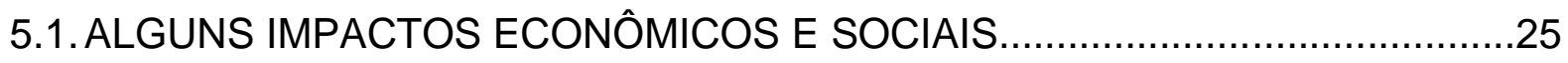

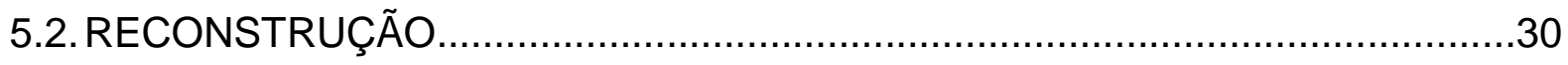

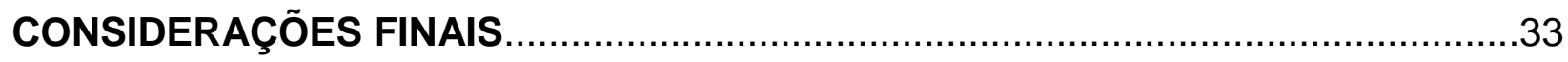

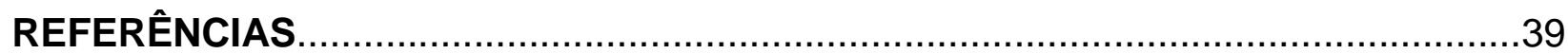

APÊNDICE A - FORMULÁRIO DINÂMICO PARA PESQUISA ON-LINE ....................47

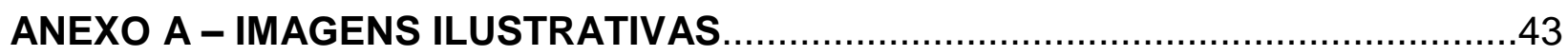




\section{INTRODUÇÃO}

Este trabalho acadêmico realizado a respeito do grande impacto na atividade turística no Bairro Francês (French Quarter), que se localiza na cidade de Nova Orleans, Louisiana, Estados Unidos da América, atingido pela catástrofe do furacão Katrina em 2005, tem por escopo analisar a ampla convulsão gerada na esfera do turismo local após o fenômeno. Esse contexto foi estudado dentro dos conceitos de sustentabilidade, considerando como norte o turismo sustentável e seus princípios de aplicação. Foram feitas, além disso, rápidas referências aos demais setores existentes e afetados como, por exemplo, economia, oferta de empregos, meio ambiente, moradias, sociedade, entre outros.

Esta pesquisa é de grande valor por se tratar de um famoso e delicado destino turístico dos Estados Unidos. O French Quarter é a parte mais antiga e famosa da cidade, sendo seu nome a designação dada como bairro central, uma zona citadina caracterizada pela sua arquitetura colonial de inspiração francesa marcada pela exuberância de suas varandas em ferro forjado. Para além de suas características arquitetônicas, o French Quarter é conhecido pela intensidade da sua vida noturna e pela existência de numerosos estabelecimentos de diversão, com destaque para os musicais.

O motivo principal que incentivou o desenvolvimento desta pesquisa foi a percepção da inobservância do conceito de sustentabilidade para a região. Assim, aponta-se como a ferramenta turismo, de maneira geral, pode auxiliar na recuperação da região de forma sustentável. 
Foram abordados assuntos que descrevem a atividade turística em áreas do planeta sujeitas a catástrofes naturais, relacionando fraquezas já vividas e o impacto no turismo local. Também foi descrito o fenômeno chamado furacão e seu respectivo funcionamento, enfatizando seus efeitos primários e secundários. Depois, o texto percorre a história do furacão Katrina, que devastou a região estudada com impactos que são percebidos até os dias atuais, assim como a história do French Quarter, antes e após o desastre, enfatizando a recuperação do bairro com a ajuda de um turismo sustentável.

A pesquisa é de natureza básica exploratória com abordagem qualitativa, através de análise bibliográfica em diversos campos do conhecimento, desde a ecologia ao turismo, da cultura à economia, entre outros. Algumas fontes de informação, como livros e conteúdo publicado sobre o assunto, foram exploradas e compiladas no intuito de se entender a complexidade do tema. 


\section{TURISMO E CATÁSTROFES NATURAIS}

Um relatório do Programa Ambiental das Nações Unidas, veiculado pelo Jornal da Ciência em 2005, divulgou que a vulnerabilidade diante de desastres naturais, como tsunamis $^{1}$ e ciclones ${ }^{2}$, é um dos maiores desafios para países desenvolvidos e, principalmente, países em desenvolvimento, como os da América Latina. Em algumas economias e, até mesmo, em partes do território de algumas nações, as desgraças provocam conseqüências devastadoras não somente no ambiente econômico, mas, também, nas esferas ambientais, políticas e sociais. O tsunami que ocorreu no Oceano Pacífico em 2004, afetando a Indonésia e outros países da região, comprometeu comunidades costeiras, recifes de coral e mangues, que são importantes fontes econômicas, além de apagar do mapa mundial algumas das Ilhas Maldivas.

Para Sawkar (2003), as ameaças ambientais transcendem a esfera tradicional de competência humana em matéria de gestão dos territórios e dos recursos naturais. Em casos pós-catástrofes naturais, pouco pode ser feito a não ser a reconstrução gradual das áreas atingidas. As zonas costeiras do planeta são altamente suscetíveis a ameaças por calamidades ambientais.

As ameaças ambientais globais atingem a população de baixa renda de maneira desproporcional, segundo o estudo As Diretrizes da Comissão de Assistência ao Desenvolvimento (2002), porque não há acesso a infra-estrutura de emergência

\footnotetext{
${ }^{1}$ Onda ou uma série delas que ocorrem após perturbações abruptas que deslocam verticalmente a coluna de água, como, por exemplo, um sismo, uma atividade vulcânica, um abrupto deslocamento de terras ou gelo ou devido ao impacto de um meteorito dentro ou perto do mar.

${ }^{2}$ Um ciclone, considerando-se a etimologia da palavra, é qualquer fenômeno de movimento atmosférico rotatório no sentido horário. Na meteorologia, os movimentos no sentido anti-horário são denominados anticiclones. Exemplos de ciclones são: tornados, furacões, tufões e outros movimentos que ocorrem quando do encontro de ventos contrários.
} 
decente a esses indivíduos. Os governos de diversos países têm o hábito de tratar como fato isolado o risco que as comunidades costeiras correm perante catástrofes naturais, que podem minar economias regionais, incluindo o setor do Turismo. Este hábito não é revertido pela ausência de políticas efetivas com caráter prioritário para uma nação. Mais ainda, alguns países são muito pobres e possuem economias fracas que dependem exclusivamente do turismo. Mais ainda, esses países sofrem de precariedade em setores básicos como alimentação, educação, estabilidade econômico-política, moradia e saúde. Este fato costuma impedir que as atenções voltem para a criação de agendas de desenvolvimento quando não se é capaz de suprir as necessidades primárias de uma nação.

Ainda em referência ao estudo citado no parágrafo anterior, há uma lacuna importante a ser preenchida entre os tomadores de decisão, como empresários e políticos, quando eles não aproveitam ao máximo as oportunidades disponíveis, como encontros e reuniões, para abordar as necessidades de desenvolvimento em curto prazo, cuidando, ao mesmo tempo, dos recursos ambientais críticos em longo prazo. $\mathrm{O}$ resultado é que as catástrofes naturais podem ser, muitas vezes, efeitos da ação predatória do ser humano, que cria sérias ameaças ambientais ao equilíbrio do ecossistema mundial ao não observar importantes políticas setoriais para a agricultura, a exploração do turismo, a produção de energia e o manejo florestal sustentável.

Marinus Groenendal, diretor no Brasil do grupo hoteleiro espanhol Serhs, afirmou em 2005 no Jornal $O$ Norte Online $^{3}$ que catástrofes naturais são entraves ao

${ }^{3}$ Jornal 0 Norte Online. Disponível em http://www.jornalonorte.com.br/turismo/?54937. Acesso dia 14/09/2005. 
desenvolvimento da atividade turística. Também é a extrema violência em algumas cidades brasileiras, como Recife, capital de Pernambuco, dando como exemplo perdas estimadas de mais de quatrocentos milhões de reais a cifras na casa das dezenas de bilhões de reais.

A cidade portuguesa de Albufeira foi atingida por um violento terremoto em $1755^{4}$, destruindo sua principal fonte de renda, a exportação de peixes e frutos secos. Sendo uma das cidades historicamente mais atingidas por catástrofes naturais, a tábua de salvação naquela época para a economia da região foi o turismo, que, a partir de 1960, começou a se desenvolver melhor. Nunes informou na Revista Turismo ${ }^{5}$, disponível em 2005 no sítio Cidade Internet, que o Brasil não sofre de catástrofes naturais como outras regiões do mundo. Esta realidade pôde ser contestada quando a National Oceanic \& Atmospheric Administration - NOAA ${ }^{6}$ e a National Aeronautics and Space Administration - NASA ${ }^{7}$ confirmaram em 2004 que o Catarina havia atingido o estado brasileiro de Santa Catarina naquele ano. Foi o primeiro furacão a ser registrado na história do oceano Atlântico Sul, afetando a cidade catarinense de Torres, entre outras áreas.

Brito publicou em 2005 e 2006, pela Universidade Federal da Paraíba ${ }^{8}$, uma compilação de estudos dizendo que, apesar de ser um forte gerador de benesses para

\footnotetext{
${ }^{4}$ Algarve, Portugal - Turismo - Albufeira. Disponível em http://www.portugalvirtual.pt/. Acesso em 19/11/2005.

${ }^{5}$ Cidade Internet. Disponível em http://www.cidadeinternet.com.br/. Acesso em 08/10/2005.

${ }^{6}$ Divisão dentro do Departamento de Comércio dos Estados Unidos da América. NOAA é um órgão para assuntos sobre Meteorologia, Oceanos, Atmosfera e Clima.

${ }_{8}^{7}$ Agência espacial americana.

${ }^{8}$ BRITO, Bruno Dantas Muniz de. Sensibilização Ambiental e Educação Turística: Uma Proposta para o Desenvolvimento Sustentável no Município do Conde - Paraíba - Brasil. Universidade Federal da Paraíba, 05, 2006.
} 
a comunidade e a economia em geral, o turismo também pode ser muito frágil e tímido ante as situações e momentos de crise. Os altos e baixos das crises econômicas podem significar o adiamento do crescimento do turismo. As crises internacionais, a alta do dólar como moeda internacional, as variações climáticas e as catástrofes naturais entram como pontos negativos que podem comprometer a indústria do turismo internacionalmente.

Salvador Briceño, diretor responsável pela Estratégia Internacional para a Redução de Desastres das Nações Unidas, diz, em matéria de 2005 da Folha Online Ciência, que a atividade humana está causando mais destruição do que as catástrofes naturais registradas no mundo ao urbanizar zonas inadequadas, contribuir para 0 aquecimento do planeta, e enfrentar despreparadamente os fenômenos que afetam a Terra. As informações foram divulgadas em setembro de 2005, no VIII Seminário de Jornalismo e Meio Ambiente, realizado na cidade espanhola de Córdoba, organizado pela Empresa Nacional de Resíduos Radiativos da Espanha e pela empresa francesa Agência EFE. Segundo Briceño, o aquecimento global causará furacões e inundações ainda mais fortes. No caso dos Estados Unidos da América, alguns estados americanos, como Flórida e Califórnia, estão mais preparados para enfrentar catástrofes, enquanto outros, como Louisiana e Mississippi, não estão. Isto se explica pela diferença de riquezas e infra-estrutura de qualidade nesses estados.

Segundo o estudo de 2002 intitulado Environment Canada's Green Lane, alguns países desenvolvidos e outros em desenvolvimento, de fato, preocupam-se com os impactos humanos à natureza e os respectivos desastres ambientais, que são formadores de catástrofes naturais, a curto e a longo prazos. Em algumas ocasiões, 
essas preocupações acabam não saindo do papel, sendo, apenas, acordos internacionais firmados, sem caráter legal, dentro dos países que participam de encontros de nações promovidos ao redor do globo terrestre. O Instituto de Ciências Sociais da Universidade de Lisboa informou em 2002 que o governo português reconhece que o progresso humano deve ser conciliado a uma prestação de contas ao meio ambiente, junto à participação da opinião pública, para que seja interpretado como progresso sustentável, ao contrário de um não progresso, com propósito de conservar ao máximo as condições ambientais naturais.

Várias regiões turísticas já tiveram conseqüências fatais devido à ação destruidora da natureza, por exemplo: Tóquio, a capital do Japão, sofreu um terremoto em $1923^{9}$, matando mais de 60 mil pessoas; as regiões da Sicília e da Calábria, na Itália, sofreram um terremoto seguido de tsunamis em $1908^{10}$, deixando mais de 120 mil mortos; a cidade montanhosa de Yungay, no Peru, sofreu um terremoto seguido de avalanches em $1970^{11}$, vitimando mais de 66 mil pessoas.

\section{DEFINIÇÃO DE UM FURACÃO}

Conforme a OMM $(2007)^{12}$, para a meteorologia ${ }^{13}$, um furacão é um tipo de sistema de baixa-pressão que geralmente se forma nas regiões tropicais. Em áreas

\footnotetext{
9 ZAGONEL, Rosa Maria. Influência da Cultura de Origem dos Descendentes de Imigrantes Japosenes no Desempenho Acadêmico e no Concurso Vestibular/2000 da UFPR. Universidade Federal do Paraná, p. 32, Curitiba, 2002.

10 Terremotos Catastróficos. Disponível em http://www.unb.br/ig/sis/catastr.htm/. Acesso em 17/05/2007.

11 Escalando na Cordillera Blanca. Disponível em http://www.larc.usp.br/ hchang/DicasCordilleraBlanca1.html. Acesso em 17/05/2007.

World Meteorological Organization. THIRD Tropical Cyclone RSMCs Technical Coordination Meeting. Disponível em http://www.wmo.ch/pages/index_en.html. Acesso em 25/04/2007.

${ }^{13}$ Ciência que estuda a atmosfera terrestre e seus fenômenos.
} 
povoadas, são considerados como altamente destrutivos. Nos trópicos ${ }^{14}$, é uma parte importante do sistema de circulação atmosférico que move calor da região equatorial para as latitudes ${ }^{15}$ mais altas.

\subsection{Uma máquina de calor}

Estruturalmente, um furacão é uma grande área giratória de nuvens e atividades de tempestade. A fonte de energia primária de um furacão é o lançamento de calor pela condensação de vapor de água que se condensa a altitudes elevadas.

\subsection{Classificação e terminologia}

Os furacões são sistemas sustentando ventos que excedem $118 \mathrm{Km} / \mathrm{h}$. Seguindo as definições da Organização Mundial de Meteorologia ${ }^{16}$ - OMM, os furacões são categorizados numa escala de 1 a 5 de acordo com a força dos ventos denominada Escala de Furacões Saffir-Simpson ${ }^{17}$. Um furacão categoria 1 tem as mais baixas velocidades de vento, enquanto um de categoria 5 tem as mais fortes velocidades de vento. Estas são condições relativas, porque as tempestades de categoria menor, às vezes, podem infligir maiores danos que as de categoria mais alta, dependendo do local

${ }^{14}$ Devido à inclinação do eixo do planeta, a Terra possui dois trópicos, são o trópico de Câncer e o trópico de Capricórnio. Estes são os paralelos geográficos limites das zonas por onde a projeção zenital dos raios do Sol cobre no correr do ano, e os solstícios representam a trajetória máxima dos raios do Sol sobre a superfície terrestre.

${ }^{15}$ Latitude é um termo usado na geografia e na cartografia. No globo terrestre, é o ângulo de um raio ao centro da Terra e que passa por determinado observador ou local, estabelecendo com o plano do equador terrestre.

${ }_{17}^{16}$ A sigla pode ser em português, OMM, ou em inglês, WMO.

17 Furacões com ventos ininterruptos de $118 \mathrm{Km} / \mathrm{h}$ (65 nós), ou mais, foram classificados por Herbert Saffir, engenheiro consultor, e Robert Simpson, então Diretor do Centro Nacional de Furacões nos Estados Unidos no início dos anos 70, que desenvolveram a TABELA SAFFIR-SIMPSON como medida de intensidade de um furacão. 
onde acontece o fenômeno. De fato, tempestades tropicais podem produzir danos significantes e perda de vida, principalmente devido a inundações.

\subsection{Bacias de formação}

A OMM define que há sete bacias principais de formação de furacões, onde a que chama mais atenção é a Bacia Atlântico Norte por ser a mais estudada de todas as bacias tropicais. O Atlântico Norte inclui o Oceano Atlântico, o Mar do Caribe e o Golfo do México. Os Estados Unidos, o México, a América Central, as Ilhas Caribenhas e o Canadá são afetados através de tempestades nessa bacia. Previsões para todas as tempestades são emitidas pelo Centro Nacional de Furacões dos EUA, segundo a NOAA (2005), em Miami, Flórida, e no Centro de Furacões Canadense, em Halifax, Nova Escócia, Canadá. Furacões que atingem o México, a América Central e as nações das Ilhas Caribenhas freqüentemente causam danos imensos.

\subsection{Efeitos primários}

A Space Science and Engineering Center $(2007)^{18}$ explica que o amadurecimento de um furacão pode lançar calor acima de uma taxa equivalente à detonação de uma bomba nuclear de dez megatons ${ }^{19}$ durante vinte minutos. Furacões no mar aberto causam grandes ondas, chuvas pesadas e ventos altos que, às vezes, afundam navios. Porém, os efeitos mais devastadores de um furacão acontecem quando eles cruzam litorais, gerando grandes precipitações de água. Os ventos altos,

${ }^{18}$ Space Science and Engineering Center. Disponível em http://www.ssec.wisc.edu/. Acesso em $17 / 05 / 2007$.

${ }^{19}$ Megaton é uma unidade de massa equivalente a 1.000 .000 de toneladas de (109 $\mathrm{kg}$ ou 1 teragrama (Tg)). O símbolo oficial para megaton é Mt, mas MT também pode ser usado. 
mais precisamente os ventos com força de furacão, podem danificar ou destruir veículos, edifícios, pontes, etc. Ventos fortes também projetam escombros soltos e tornam o ambiente ao ar livre muito perigoso. As ondas de tempestade causam um aumento do nível do mar, que pode inundar comunidades litorâneas, sendo este um dos piores efeitos. Oitenta por cento das vítimas acontecem quando o furacão golpeia a orla. Rios transbordam, estradas ficam intransitáveis e deslizamentos de terra podem acontecer.

\subsection{Efeitos secundários}

Os efeitos secundários de um furacão são, com freqüência, igualmente catastróficos, incluindo doenças, onde o ambiente molhado do resultado de um furacão, combinado com a destruição de instalações de serviços de saúde pública e um clima tropical morno, podem induzir epidemias de doenças por bastante tempo depois da passagem do fenômeno. Também, dificuldades de locomoção são causadas por furacões que destroem, freqüentemente, pontes chaves, viadutos e estradas, complicando os esforços para transportar comida, água limpa e medicamentos para as áreas necessitadas. Ademais, atividades econômicas, serviços essenciais e infraestrutura danificada são danos que levarão determinado período de tempo para serem restabelecidos a um ponto organizado e possivelmente satisfatório. 


\section{FURACÃO KATRINA}

O Furacão Katrina, como informa o National Hurricane Center $(2005)^{20}$, foi um grande furacão, uma tempestade tropical que alcançou a categoria 5 na Escala de Furacões Saffir-Simpson. Os ventos do furacão alcançaram mais de $280 \mathrm{Km} / \mathrm{h}$, e causaram grandes prejuízos na região litorânea do sul dos Estados Unidos, especialmente em torno da região metropolitana de Nova Orleans, em 29 de agosto de 2005, onde mais de um milhão de pessoas foram evacuadas. O furacão passou pelo sul da Flórida, causando em torno de dois bilhões de dólares de prejuízo e seis mortes diretas. O furacão Katrina custou 972 mortes na Louisiana, de acordo com a contagem final do governo americano no dia 4 de outubro de 2005, sendo um dos furacões mais destrutivos a ter atingido os Estados Unidos. O evento paralisou muito a atividade de extração de petróleo e gás natural dos EUA, uma vez que boa parte do petróleo estadunidense é extraída no Golfo do México. Mais de cinco milhões de pessoas ficaram sem energia elétrica na região da Costa do Golfo, tendo levado semanas para que a energia fosse parcialmente restaurada, já que nos bairros mais afetados o quadro de serviços básicos prestados ainda é irregular.

\subsection{Conseqüências imediatas}

O jornal americano Sun Herald noticiou em 2005 que os habitantes que não conseguiram sair da cidade foram levados ao Superdome para esperar a passagem da tormenta. Katrina destroçou o telhado do estádio, onde 25.000 pessoas amontoavamse em pânico. A área do lado de fora do estádio foi, como quase toda a cidade,

${ }^{20}$ KNABB, Richard D., RHOME, Jamie R., and BROWN, Daniel P. Tropical Cyclone Report Hurricane Katrina. National Hurricane Center. Miami, p. 01-15, 2005. 
alagada. A situação dentro do edifício foi descrita como caótica, conforme relatórios policiais posteriores resumindo lutas, furtos e roubos, mortes e, possivelmente, estupro, o qual não foi confirmado oficialmente. A agência Federal Emergency Management Agency - FEMA ${ }^{21}$ anunciou que os 25.000 confinados no Superdome foram realocados no estádio Astrodome, de Houston, Texas. O Superdome foi reparado a um custo de US\$ 140 milhões, e reinaugurado em 25 de setembro de 2006.

Com base no estudo de Sheikh, The Impact of Hurricane Katrina on Biological Resources $(2005)^{22}$, como conseqüência da tempestade, muitos problemas apareceram. Alguns dos diques ${ }^{23}$ que protegiam Nova Orleans não conseguiram conter as águas do Lago Pontchartrain ${ }^{24}$, que afluiu cidade adentro, inundando mais de $80 \%$ da cidade. Cerca de 200 mil casas ficaram debaixo da água em Nova Orleans. O solo sedimentar da cidade impermeabilizou o terreno, tornando-o, de fato, um lago artificial. No dia 13 de outubro, o exército americano finalmente concluiu a drenagem das águas na região, bombeando-as de volta ao Lago Pontchartrain. $O$ furacão causou grandes estragos na cidade, entre elas danos no sistema de abastecimento sanitário e de esgoto. Como resultado, os habitantes só puderam retornar aos poucos para a cidade após a passagem do furacão Rita próximo à divisa da Louisiana com o estado do Texas, a partir do dia 26 de setembro. A maioria dos habitantes da cidade foi evacuada

${ }^{21}$ Agência Federal de Gerenciamento de Emergências: agência do governo dos EUA direcionada a serviços de emergência na ocorrência de desastres, tanto naturais quanto provocados pelo homem. É integrante do Departamento de Segurança Interna (Department of Homeland Security).

${ }^{22}$ SHEIKH, Pervaze A. The Impact of Hurricane Katrina on Biological Resources. Congressional Research Service. 2005.

${ }_{23}$ Dique é uma obra de engenharia com a finalidade de manter determinadas porções de terra secas. Sua estrutura possibilita regular o fluxo de água em uma determinada área.

${ }^{24} \mathrm{O}$ Lago Pontchartrain é um lago localizado no sudeste do estado americano de Louisiana. É o segundo maior lago de águas salgadas, atrás somente do Grande Lago Salgado, e é o maior lago da Louisiana. Possui uma área de 630 quilômetros quadrados, e uma profundidade média de apenas 3,5 metros. $\mathrm{Na}$ margem sul do lago localiza-se a cidade de New Orleans, a maior cidade do estado, bem como os terrenos de menor altitude da Louisiana. 
para outras cidades dos estados da Louisiana, do Texas e do Missouri. Porém, vários dos habitantes evacuados foram transportados para regiões distantes como Washington, Ontário e Illinois.

A área federal do desastre foi colocada sob o controle da FEMA, na época comandada por M. Brown, e da Guarda Nacional ${ }^{25}$. Na noite de 31 de agosto, o prefeito de Nova Orleans Ray Nagin declarou lei marcial ${ }^{26}$ na cidade, e disse que os policiais não precisavam se preocupar com os direitos civis para deter os saqueadores. A interrupção do suprimento de petróleo, importações e exportações causadas pela tempestade trouxeram seqüelas enormes para a economia americana e, possivelmente, a global em menor escala.

No dia 4 de outubro, Nagin informou que 3 mil trabalhadores, cerca da metade da força de trabalho da cidade, foram demitidos devido à falta de verba para 0 pagamento de salários. O prefeito de Nova Orleans destacou que a medida só afetaria os funcionários públicos dos serviços não essenciais, e não a polícia, os bombeiros e os hospitais. O anúncio das demissões foi feito no mesmo momento em que as autoridades davam como terminadas as buscas por cadáveres na cidade.

Segundo o Departamento de Trabalho americano (2005), após a passagem do furacão Katrina, a economia americana perdeu 35 mil empregos em setembro, depois da criação de 211 mil em agosto, e a taxa de desemprego chegou a pouco mais de $5 \%$

\footnotetext{
${ }^{25}$ A Guarda Nacional dos Estados Unidos da América é um componente importante e significativo da reserva militar das forças armadas dos Estados Unidos.

${ }^{26}$ Chama-se lei marcial o sistema de leis que tem efeito quando uma autoridade militar, geralmente após uma declaração formal, toma o controle da administração ordinária da justiça e, normalmente, de todo o Estado. Pode ser, também, uma lei militar instituída num país em ocasião de perigo, e que provoca a suspensão da lei ordinária. Mais ainda, essa lei pode ser utilizada em situações de calamidade pública.
} 
contra os dois décimos a menos de pontos percentuais do mês de agosto. $O$ departamento modificou os procedimentos de cálculo para refletir de melhor maneira os efeitos sobre o emprego nas zonas afetadas pelo Katrina.

A UCLA ${ }^{27}$ informou em 2005 que o furacão Katrina teria, na verdade, um impacto mínimo na economia americana, reduzindo o crescimento em um ponto e meio percentual. Segundo seus cálculos, os investimentos para reconstrução das regiões afetadas impulsionam o crescimento na mesma proporção nos anos consecutivos.

\section{FRENCH QUARTER - NOVA ORLEANS}

O Guia de Viagem Michelin - Nova Orleans (2006) diz que bairro é conhecido por seu legado multicultural, em especial pelas influências culturais francesas, espanholas e afro-americanas, sua música e sua culinária, sendo considerado um destino turístico internacional bastante visitado graças aos seus vários festivais. Entre eles, os mais importantes são o Mardi Gras, um carnaval católico, e o Southern Decadence, um evento festivo mais voltado ao público homossexual masculino. Ambos são grandes festivais que atraem anualmente milhões de turistas.

Muitos dos edifícios datam de antes de Nova Orleans tornar-se parte dos Estados Unidos, embora haja alguns do fim do século XIX e começo do século XX na área, também. Desde a década de 1920, os edifícios históricos são protegidos por lei e não podem ser demolidos, e qualquer renovação ou construção na vizinhança deve ser feita de acordo com regulamentos de modo a estar compatível com o estilo de arquitetura histórico do período.

\footnotetext{
${ }^{27}$ Nome de um departamento da University of California, Los Angeles, EUA.
} 
Um tempo depois que os Estados Unidos compraram a Louisiana, descendentes de colonos franceses viviam na área do bairro em estudo. Quando os americanos começaram a se mudar para a região após a compra da Louisiana, eles passaram a construir mais acima do rio Mississipi, ao longo da atual Canal Street (os latifundiários locais haviam retido o arquiteto e avaliador Barthelemy Lafon para subdividir suas propriedades para criar um subúrbio americano). A calçada central do extenso bulevar tornou-se um lugar onde as duas contenciosas populações encontram-se para trabalhar. Como tal, ficou conhecido como "neutral ground".

Na década de 1980, muitos residentes do bairro foram despejados ou afastados por aluguéis crescentes enquanto os valores das propriedades aumentaram dramaticamente. A vizinhança tornou-se cada vez mais desenvolvida em benefício do turismo. O French Quarter remanesce uma combinação de propriedades residenciais e comerciais.

O livro Fodor's - Nova Orleans (1998) conta que o French Quarter e a Bourbon Street são atrações turísticas internacionalmente conhecidas pela ativa vida noturna, pela St. Charles Avenue, casa da Universidade de Tulane e da Universidade de Loyola, e até pelas várias mansões do século XIX.

O French Quarter, principal ponto turístico de Nova Orleans, é mais conhecido na região como The Quarter. Além de ser um dos pontos mais visitados por turistas naquele país, o turismo é classificado como uma das principais fontes de renda do local. Alguns dos vários hotéis, bares e clubes noturnos no bairro são o Jackson Square, a St. Louis Cathedral e o Mercado Francês, incluindo o Café du Monde, famoso 
por seu café ao leite e, mais ainda, o Preservation Hall. Dois museus estão localizados no French Quarter, um é uma ex-Casa da Moeda americana e outro é dedicado à II Guerra Mundial.

O Mardi Gras significa, literalmente, Terça Gorda, e é a celebração mais famosa de Nova Orleans, que acontece na estação de carnaval. Todo ano, mais de um milhão de turistas comparece ao evento. Os turistas internacionais que atendem anualmente ao festival experimentam música, comida, artes e artesanato típicos. A obra Jazz From New Orleans To the New Jazz Age (1996) diz que, apesar do nome, o festival não está centralizado unicamente no jazz, possuindo uma grande variedade de música, incluindo música nativa da Louisiana e de outros músicos nacionalmente conhecidos.

\subsection{Riscos}

Um estudo de 2000 da Louisiana State University informou que o estado da Louisiana tem um ambiente altamente dinâmico e potencialmente perigoso. As ameaças incluem ventos induzidos por furacões; ondas e elevações de tempestades do Golfo do México ao sul; inundações extensivas nas áreas baixas pelo Rio Mississippi ao norte; e os vários impactos de inundações, furacões, tempestades, tempestades de gelo, secas, e queimadas por todo o estado. As tentativas de minimizar os efeitos desses eventos problemáticos podem somente ser feitas com um fluxo de informações oportunas, exatas e detalhadas.

De todas as ameaças às vidas e aos bens de propriedades no French Quarter, nenhuma ultrapassa as de um furacão. Virtualmente, todo o litoral da Louisiana está perto ou abaixo do nível do mar, fazendo o estado altamente suscetível a ondas e 
elevações do nível do mar durante tempestades tropicais e furacões. No século passado, o centro-sul da Louisiana experimentou o que parece ser o maior número (6) de landfalls ${ }^{28}$ de grandes furacões (categoria 3 em diante) do que em qualquer outro lugar nos Estados Unidos continental. Quando unidos com o caráter topográfico baixo do sul da Louisiana, esses encontros indicam que as áreas densamente povoadas, como o Bairro Francês, lideram entre as mais propícias a potenciais impactos sociais e a mortalidade e perdas econômicas, desde as importantes instalações comerciais e culturais à atividade turística na capital do jazz e do Mardi Gras. Na área metropolitana de Nova Orleans, mais de 100 mil pessoas estão em risco no evento de um furacão severo, e o total de seguros por perdas poderia facilmente exceder os US\$ 7 bilhões.

A Agência Cubana de Noticias - AIN divulgou em 2005 que a política de corte dos gastos públicos havia suprimido mais se 70 milhões de dólares do Corpo de Engenheiros de Nova Orleans, uma redução de $44 \%$ no orçamento, resultando, deste modo, no arquivamento dos planos de fortalecer os diques e melhorar o sistema de bombeamento e drenagem das águas. O rio Mississipi transporta às planícies cerca de um bilhão de toneladas de sedimentos por ano, formando extensos pântanos. Todavia, as indústrias de construção civil e do turismo vêm se expandindo sobre esses pântanos com o beneplácito das autoridades locais e, assim, todo o sistema de drenagem vem sendo alterado, posto que os pântanos, tais como os manguezais, cumprem um papel fundamental de amortização de enchentes. A Agência ainda argumenta que os alertas sobre uma catástrofe sócio-ambiental foram ignorados em nome do desenvolvimento e da acumulação de capital, sobretudo na área do turismo.

\footnotetext{
${ }^{28}$ Termo utilizado para definir o momento em que o olho de um furacão atinge terra firme.
} 


\section{IMPACTOS DO FURACÃO KATRINA NO FRENCH QUARTER}

5.1. Alguns impactos econômicos e sociais

A Bush Administration alertou em 2005 que o furacão redistribuiu a população de Nova Orleans através dos Estados Unidos, desde Houston a Seatle, ou seja, criando um alto impacto nas vidas dos que moravam na cidade alagada. A destruição do Katrina levantou assuntos de políticas públicas sobre gerenciamento de emergências, política ambiental, pobreza e desemprego. Uma investigação do Congresso americano acusou que a FEMA e a Cruz Vermelha "não tiveram uma capacidade da logística suficiente o bastante para suportar inteiramente o número maciço de vítimas na Costa do Golfo". Adicionalmente, a própria responsabilidade pelo desastre foi colocada em todos os três níveis do governo daquele país.

Segundo o estudo acadêmico Political Science Subject Guide: New Orleans Reconstruction (2005) ${ }^{29}$, Nova Orleans foi atingida em cheio pelo furacão Katrina em 29 de agosto de 2005. O Katrina foi categorizado, inicialmente e antes de atingir a cidade, como um furacão de categoria 5 na Escala de Furacões Saffir-Simpson, a mais destrutiva categoria de todas. O Katrina, porém, foi rebaixado posteriormente a um furacão categoria 4, poucas horas antes do real impacto.

A prefeitura de Nova Orleans instituiu uma evacuação obrigatória de emergência a toda a cidade, a primeira ordem desse gênero implementada na região. Porém, por causa da falta de planejamento de transporte, principalmente aos milhares de pessoas que não possuíam carros, muitos habitantes da cidade foram forçados a ficar nela.

\footnotetext{
${ }^{29}$ CRANE, Janet. Political Science Subject Guide: New Orleans Reconstruction. University of New Orleans, New Orleans. 2007.
} 
Outros decidiram simplesmente continuar na cidade por vontade própria. Vários dos milhares de habitantes que permaneceram foram movidos para o estádio esportivo Superdome.

O French Quarter foi atingido por ventos de até 200 quilômetros por hora, e cerca de $40 \%$ da cidade foi alagada, em virtude do furacão Katrina. Milhares de policiais foram enviados ao French Quarter para tentar manter o controle do local, e foi instituída lei marcial pelo prefeito de Nova Orleans, Ray Nagin.

Em 30 de agosto de 2005, dois dos diques que cercavam Nova Orleans cederam à grande pressão das águas do Lago Pontchartrain. Os reservatórios desses diques já estavam acima da capacidade graças ao furacão. Por causa disso, $80 \%$ da cidade foi alagada, com a água atingindo uma altura de até 7,5 m. O estudo Hurricane Katrina: Preliminary Estimates of Commercial and Public Sector Damages (2005) informa que as companhias seguradoras estimaram, nas estatísticas mais altas, estragos de 10 a 25 bilhões de dólares no French Quarter.

O French Quarter, assim como a maioria da partes da cidade que se desenvolveram durante o século XIX, foi uma das áreas a permanecer substancialmente secas, já que ela foi construída em terras impermeáveis que predominavam antes do sistema de diques de Nova Orleans e ficam cinco metros acima do nível do mar. Algumas ruas experimentaram inundações menores, e diversos edifícios se submeteram a danos significativos dos ventos. A maioria dos pontos de referência sofreu somente danos de segundo grau e muitos já têm aberto portas ao público desde então ou têm agendado a reabertura. The Quarter escapou amplamente 
aos saques e à violência depois da passagem do fenômeno, e quase todas as belas antiqualhas e lojas de arte no French Quarter, por exemplo, permanecem intocadas.

O Prefeito Ray Nagin oficialmente tornou acessível o French Quarter em 26 de setembro de 2005 aos donos de negócios para inspecionarem suas propriedades e iniciar o processo de limpeza. Em um mês, grande parte do comércio do French Quarter estava novamente disponível ao público geral.

Em 2005, Robert Meyers, presidente da Gab Robins' Insurance, constatou ${ }^{30}$ em 3 de outubro que ônibus interestaduais e operadoras de turismo que deixavam clientes nos cassinos de Nova Orleans não sustentavam muitos danos após a passagem do furacão Katrina, apesar de estarem, na época, sem mais destinação para seus fregueses. Os varejistas, os hotéis e outros negócios relacionados ao entretenimento nas regiões discutiram com Meyers diariamente sobre as situações de lidar com suas numerosas ações de seguro.

A AIN informou em 2005 que o país mostrou-se incapaz de ser previdente e de alocar recursos com eficiência. O furacão Katrina afetou a produção de bens e serviços ambos em terra e mar por todo o país naquele território. A maioria dos serviços turísticos locais é baseada em atividades marítimas, sendo que o ambiente de terra é igualmente crítico para o setor. Como já mencionado anteriormente, a infra-estrutura de cidades, incluindo eletricidade, água, redes de comunicação, estradas e portos é exposta aos elementos de ventos fortes, mares elevados e chuvosos, deslizamentos de terra e invasões de detritos e lama. A vulnerabilidade da infra-estrutura freqüentemente

\footnotetext{
${ }^{30}$ Report to the Community 2005 - 2006. UJA Federation of New York, p. 10-11, Nova lorque, 2006.
} 
se traduz em perdas potenciais. Quanto mais elevada a vulnerabilidade física, maiores serão as perdas econômicas.

Prejuízos por interrupções nos negócios em todos os setores de serviços totalizaram aproximadamente mais de $92 \%$ do total na região afetada, incluindo, conforme o livro Letters from New Orleans (2005), o bairro francês. As perdas nos principais serviços produtivos (turismo, finanças e distribuição) atingiram $80 \%$ das perdas totais devido ao fechamento dos negócios. As perdas em salários à população economicamente ativa somam mais de $13 \%$ do total para todas as instituições da economia. Como esperado, as estimativas de perdas salariais foram concentradas no turismo em quase $40 \%$ e nos serviços financeiros em $34 \%$. Os salários perdidos no setor público deram-se em menor escala, mesmo sendo o setor em menção o segundo maior empregador na região. Este elemento deve-se ao fato de a maioria dos empregados no governo e em outras atividades econômicas continuar recebendo durante e depois de um furacão. Estes últimos dados fazem parte, ainda, do levantamento de Robert Meyers.

Segundo o jornal eletrônico Folha Online (2005), em 31 de outubro de 2005, a passagem do furacão Katrina pelo sul dos Estados Unidos afetou as atividades de companhias aéreas que operam na região afetada. Os turistas que tinham The Quarter no roteiro também foram prejudicados, tendo de alterar ou cancelar suas viagens. A United Airlines afirma que todos os vôos para Nova Orleans foram cancelados até o dia 4 de outubro. A American Airlines seguiu a mesma linha e cancelou todos os vôos que iam para Nova Orleans, assim como aqueles que saiam da cidade. 
Em análise do artigo Hitting the Economy (2005), o consultor de vendas da ADV Operadora de Turismo, Reno de Paula, disse que o impacto do furacão entre as agências de turismo brasileiras foi menor, já que o French Quarter não é uma localidade que tem procura no Brasil o ano inteiro, ao contrário de, por exemplo, Manhattan, Nova York. A Connection Line Intercâmbio Cultural e Viagens também não enfrentou complicações por causa do Katrina, informando que a agência embarcou diversos passageiros para os Estados Unidos, mas nenhum deles tinha como destino as áreas afetadas.

De acordo com o sítio eletrônico de notícias Último Segundo (2005) e baseado em informações do The New York Times (2005), enquanto a costa do Golfo se recupera da devastação do Katrina, os negócios on-line se esforçam para medir o impacto das perdas de meio milhão de consumidores por semanas ou meses. Agências de turismo on-line, como Expedia, Travelocity e Orbitz, certamente estão sentindo o impacto mais forte do que outros vendedores da Internet. Eles não tiveram somente uma enxurrada de ligações cancelando as viagens para lugares na costa do Golfo do México, como o bairro em estudo, e pedindo o dinheiro de volta, mas, também, milhares de clientes desencorajados a voar para Nova Orleans.

Dentre outras ações já tomadas, a Travelocity mandou e-mails para os 14 mil clientes que haviam reservado vôos, hotéis e aluguel de carros nas áreas atingidas pela tormenta. A companhia e muitas empresas aéreas desconsideraram as taxas de cancelamento e de remarcação de data que geralmente cobram. As ligações para os centros de informação da Travelocity tiveram picos desde que a tempestade atingiu 
Nova Orleans, com os consumidores esperando entre 20 e 30 minutos até conseguir falar com um atendente.

Em 16 de setembro de 2005, a agência Reuters noticiou que no Snug Harbor, palco no French Quarter que acolhia alguns dos mais cotados músicos de jazz do mundo, não havia música desde a catástrofe. A música voltou aos seus palcos somente em 14 de outubro de 2005, com Ed Petersen \& the Ultimate Test em uma apresentação gratuita. A mesma coisa se repete no Donna's, no Preservation Hall e em vários outros lendários clubes de jazz e blues espalhados pelo French Quarter. O veterano cantor de jazz Germaine Bazzle fez a última apresentação no local em uma noite de sábado no final de agosto, um dia antes da passagem do furacão Katrina, que transformou Nova Orleans em uma cidade fantasma por dias. Muito da antiga atividade de entretenimento que havia antes na cidade já tem encontrado seu caminho de volta, conforme o artigo Blues for New Orleans: Mardi Gras And America's Creole Soul (2006). Fats Domino, astro dos gêneros musicais blues e $R \& B$ de Nova Orleans, tentou continuar na cidade apesar do Katrina, mas teve que ser resgatado depois de sua casa ser inundada. Ellis Marsalis, pianista e patriarca do jazz em Nova Orleans, e sua banda voltaram à atividade rapidamente, logo após o bombeamento total das águas que inundaram a cidade e o retorno da luz elétrica ao Bairro Francês.

\subsection{Reconstrução}

Como informou em 2005 o serviço de notícias do sítio eletrônico Terra, em 2 de outubro de 2005, a movimentação voltava ao famoso bairro francês de Nova Orleans. Dezenas de bares e uma igreja abriram suas portas pela primeira vez desde que os 
furacões Katrina e Rita forçaram a evacuação de, aproximadamente, 1,4 milhão de pessoas da região arrasada. Dias depois, as autoridades da destruída capital do jazz permitiram que os moradores regressassem ao bairro francês e às cidades próximas, e, mais adiante, o reduto da festa e da música retornou com a diversão comum na noite do French Quarter. O renomado percussionista Jason Marsalis disse que a destruição de bairros velhos, cuja população muitas vezes é, sobretudo, negra e pobre, pode acabar afetando adversamente o cenário musical. Isto devido ao fato de a música de Nova Orleans falar de seu povo, e muitas das casas mais velhas terão que ser derrubadas, sendo que boa parte da cultura da região também poderá ir embora.

Segundo informações do artigo A New Agenda for the Gulf Coast (2007), a água potável havia sido restabelecida em toda a cidade de Nova Orleans em 9 de outubro de 2006; além disso, montes de lixo ainda se acumulavam nas ruas até setembro do mesmo ano. Nas esquinas, os policiais patrulham a área normalmente ao passo em que os farristas já retornavam após as noites de festas poucas semanas após o Katrina. Em novembro de 2005 , os hospitais da cidade haviam reaberto suas portas para funcionamento em quase total capacidade, enquanto as emergências continuaram a funcionar em um barco-hospital da Marinha americana no porto de Nova Orleans, que atuou como apoio por todo o período crítico após a passagem do furacão Katrina. $\mathrm{O}$ prefeito de Nova Orleans Ray Nagin (Repopulating New Orleans, 2006) colocou suas esperanças de recuperação para a cidade nos cassinos. A ousadia de Nova Orleans é permitir os jogos de apostas nos nove hotéis que têm mais de 500 quartos, e que estão localizados quase todos na famosa Canal Street do bairro francês, em um setor que sofreu poucos danos pelas inundações. 
A Bush Administration, segundo o sítio da Casa Branca (2005), aprovou mais de US\$ 63 bilhões em ajuda aos desabrigados e aos programas de reconstrução das regiões afetadas pelo furacão Katrina, incluindo o pouco atingido French Quarter. Os jogos de apostas são legalizados naquela comarca desde 1993, ao ponto de alguns cristãos conservadores dizerem, com fundamentação apenas religiosa, que a catástrofe do Katrina foi um castigo de Deus pelos pecados na região.

Segundo a Reuters (2005), o Bairro Francês ficava em terreno mais alto e escapou ao furacão Katrina relativamente intacto, poupando maiores esforços em reconstrução. O prefeito Ray Nagin usa a música como palavra de ordem quando tenta reativar a cidade, onde hoje já há um equilíbrio entre o número de moradores e de policiais, ao contrário dos inúmeros soldados e equipes especializadas logo após a catástrofe. Com o lento e gradual retorno dos turistas, o legendário cenário musical da cidade também foi ressuscitado. Críticos dizem que as construtoras e o próprio turismo, que aos poucos retorna à região e ao French Quarter, já transformaram a cidade, que inicialmente virou um local de festas na Bourbon Street, em lugar dos atuais desfiles de rua do Mardi Gras. 


\section{CONSIDERAÇÕES FINAIS}

A vulnerabilidade perante desastres da natureza que os países apresentam, considerando-se a ação predatória do ser humano ao equilíbrio do meio ambiente, dáse, em grande parte, à escassez de políticas sérias em diversos setores da economia global. Talvez essa situação deva-se ao fato da inadimplência por parte de países capacitados a tomar decisões efetivas, ou à dificuldade que países economicamente fracos têm de enfrentar seus próprios problemas internos, inviabilizando a atenção necessária para ações pró-ambientais.

Ameaças como tsunamis, terremotos e furacões sempre existiram, mas nunca se registrou tantas delas em larga escala e em um curto período de tempo na história da humanidade como nos anos atuais. Exemplo disto é o furacão Katrina, que teve resultados devastadores no sudeste dos Estados Unidos, no Golfo do México, evacuando milhões de pessoas, deixando milhares de mortos e desabrigados. Além de ter sido o mais destruidor de toda a história americana, o Katrina poderá trazer prejuízos em escala global em longo prazo, seja na esfera das indústrias do petróleo ou do turismo, entre outras, não esquecendo os impactos sociais ocorridos nas regiões afetadas.

As áreas litorâneas são freqüentemente os primeiros ambientes a experimentar os impactos prejudiciais ao turismo possivelmente causados por catástrofes naturais. Controles de planejamento e gerenciamento podem reduzir o impacto nos ambientes litorâneos e assegurar que os investimentos em produtos turísticos apóiem um turismo do tipo náutico e sustentável. 
O erro político dos Estados Unidos de diminuir recursos financeiros destinados à proteção artificial de Nova Orleans por meio de diques contra enchentes do Lago Pontchartrain e do Rio Mississippi resultou na catástrofe existente pós-Katrina. A ineficiência imediata de órgãos governamentais no país que, em teoria, é o mais preparado para quaisquer casos de emergência nacional, mais os transtornos gerais observados em seqüência, mostraram ao mundo que nenhuma nação está completamente livre de eventos similares. Até mesmo a falta de dinheiro para se aplicar na ajuda a uma catástrofe de grande porte pôde ser vista.

A cidade de Nova Orleans, que desde seus princípios na colonização francesa até os tempos de hoje, com sua internacionalmente conhecida vida cultural, sempre foi uma calamidade premeditada devido à sua altitude abaixo do nível do mar. A região metropolitana da cidade que se situa em local estratégico para os Estados Unidos continuou crescendo ao longo dos séculos até chegar aos milhares de habitantes, mesmo com o claro conhecimento de sua condição delicada perante catástrofes naturais. Esta sempre foi a realidade de Nouvelle Orleans, como os franceses chamaram a cidade em sua fundação, descartando desgraças causadas pelo homem, como guerras e incêndios, que tiveram menor poder de estrago. Múltiplas advertências foram feitas de que furacões ou enchentes poderiam causar o caos na cidade.

O turismo desenvolveu-se fortemente no French Quarter. A vida cultural floresceu em uma das maiores comunidades afro-americana dos Estados Unidos, tornando Nova Orleans em uma região de população cosmopolita, poliglota e multicultural. Porém, períodos de dificuldades variadas aconteceram na história da 
cidade, como recessão econômica e epidemias de febre amarela. Mesmo assim, o turismo passou a crescer gradualmente.

Todo o litoral da Louisiana encontra-se abaixo do nível do mar, e a capital do jazz e cidade do blues e do Mardi Gras não recebeu o cuidado preciso, não somente por sua importância para os Estados Unidos, mas pelo fato de possuir um dos maiores índices de pobreza naquele país. Os avisos sobre uma adversidade sócio-ambiental podem ter sido desconsiderados em prol do adiantamento econômico e do acúmulo de riquezas, em especial no campo do turismo.

Nova Orleans foi impactada profundamente pelo furacão Katrina, criando um ambiente de caos total e desordem sócio-econômica. Os diques não suportaram a destrutiva força dos ventos do furacão Katrina, e as perdas deram-se em todas as áreas importantes, como distribuição, petróleo, turismo, empregos, saúde, educação, transportes, política, sociedade, entre outras.

O impacto do furacão Katrina foi menor em empresas do ramo turístico que tinham poucas ou quase nenhuma atividade relacionada à região afetada pela tormenta, citando, por exemplo, algumas agências de viagens brasileiras, para as quais os maiores destinos são cidades diferentes. Alguns empreendimentos do turismo sofreram mais, como agências de viagem e operadoras de turismo residentes nos Estados Unidos, e negócios de e-commerce relacionados à atividade turística. A vida cultural da região metropolitana de Nova Orleans também foi seriamente afetada, de músicos a apresentadoras de strip-tease, ou de eventos culturais de grande porte a pequenas celebrações em vielas orleaninas. 
A esperança na reconstrução da cidade sempre foi um fato peculiar, avaliandose o potencial que as obras de reconstrução proporcionam e a enorme quantidade de dinheiro de que necessitam. O atualmente possível retorno gradativo a Nova Orleans é uma marcha significante ao regresso à normalidade, assim como foi a reabertura de serviços essenciais à vida humana, como hospitais, policiamento e corpos de bombeiro.

Hotéis de jogos da sorte, fortes empreendimentos turísticos, podem ser a solução imediata para o início de uma volta humilde do turismo nas áreas que o furacão Katrina passou de forma arrasadora, principalmente o pouco lesado bairro francês. Contudo, a gloriosa Nova Orleans de dois anos atrás está, ainda, longe de voltar a ser o que foi, um poderoso centro cultural berço de tendências mundiais. A infra-estrutura indispensável à atividade turística está sendo aos poucos "recauchutada". Entretanto, é duvidoso que apenas a economia de mercado seja capaz de conciliar toda a façanha de reconstrução, desconsiderando planos de apoio social a vitimados pela catástrofe da natureza. Estratégias de ação em diversas escalas, tanto políticas, econômicas e sociais, como de prevenção a futuras calamidades humanas e naturais, deverão ser desenvolvidas, como a criação de entidades não governamentais e instituições públicas, similares à FEMA e à Cruz Vermelha, preparadas para casos de emergência.

Em 13 de setembro de 2005, o Aeroporto Internacional Louis Armstrong estava reaberto para carga e vôos comerciais. Obras como o reparo de pontes, vias de acesso, entre outras similares logo recebiam estímulos políticos e financeiros para serem concluídas o quanto antes, apesar de o esforço real ter sido ligeiramente mais lento. $\mathrm{O}$ governo, nas escalas municipal, regional e federal, junto a organizações independentes e instituições privadas, de pequeno a grande porte, articulavam-se para concretizar 
ações em prol da reconstrução da cidade, assim como do French Quarter, e estudar pesquisas e políticas que norteassem o futuro desenvolvimento geral da região.

Nova Orleans foi contemplada pelo turismo logo após o furacão Katrina, sendo alvo do que poderia ser considerado como "turismo de desastre", ou seja, o ato de viajar a uma área de desastre(s) como uma matéria da curiosidade. O comportamento costuma ser incômodo por atrapalhar operações de salvamento, resgate e recuperação. Em compensação, algumas comunidades como o French Quarter deram boas-vindas a grupos organizados de excursões como meios de publicidade frente à escala de destruição para atrair mais ajuda à cidade.

The Quarter deve apreciar o turismo, em longo prazo, como uma ferramenta de enorme valia na assistência à reconstrução e reorganização de suas atividades normais, que, certamente, envolvem fortemente a atividade turística. A maioria dos turistas é responsável por respeitar e conservar o equilíbrio econômico, ambiental e sócio-cultural de uma localidade. Ações de pequeno e médio portes são necessárias, como apoiar a integridade de culturas locais ao favorecer negócios que conservem a herança cultural, participando da economia regional ao comprar bens ali desenvolvidos. Assim, é incentivada a conservação dos recursos em uma procura por empreendimentos que são ambientalmente conscientes, utilizando-se a menor quantidade possível de recursos não renováveis.

A cidade ainda possui quilômetros e quilômetros em ruínas, ainda que aqueles que exclusivamente estiveram na cidade pós-flagelo têm de fato uma noção profunda de como muito já tem sido feito desde então. Dificilmente será fácil repovoar Nova 
Orleans assim como ela era antes de tudo, com quase meio milhão de habitantes. $\mathrm{O}$ turismo terá que superar a presente escassez de recursos e a falha oferta de serviços, que palmo a palmo irão regressando à normalidade.

O turismo como ferramenta pode, efetivamente, ajudar na recuperação da cidade de Nova Orleans e seu ilustre Bairro Francês ao ser aplicado visando políticas de sustentabilidade, levando essas regiões a patamares de inclusão econômico-sociais maiores e melhores que antes da passagem do fenômeno Katrina. 


\section{REFERÊNCIAS}

Agence France-Presse. Disponível em http://www.afp.com/, último acesso dia 14/09/2005.

Algarve, Portugal - Turismo - Albufeira. Disponível em http://www.portugalvirtual.pt/. Acesso em 19/11/2005.

ATKINS, Ronald. Jazz From New Orleans To the New Jazz Age. Carlton Book, New Orleans, 1996.

BOURG, Gene. Fodor's - Nova Orleans. Julio Louzada. New York, 1998.

BRITO, Bruno Dantas Muniz de. Sensibilização Ambiental e Educação Turística: Uma Proposta para o Desenvolvimento Sustentável no Município do Conde Paraíba - Brasil. Universidade Federal da Paraíba, p. 05, 2006.

BURTON, Mark L. Hurricane Katrina: Preliminary Estimates of Commercial and Public Sector Damages. University of Tennessee and Marshall University, Huntington, 2005.

Cidade Internet. Disponível em http://www.cidadeinternet.com.br/. Acesso em 08/10/2005.

CRANE, Janet. Political Science Subject Guide: New Orleans Reconstruction. University of New Orleans, New Orleans. 2007.

Dollars and Sense The Magazine of Economic Justice. Disponível em http://www.dollarsandsense.org/. Acesso dia 28/09/2006.

DPU- Impact of Hurricanes on the BVI Economy. Disponível em http://dpu.gov.vg/. Acesso dia 16/10/2005.

Environment Canada's Green Lane. Disponível em http://www.ec.gc.ca/. Acesso dia 02/11/2005.

Folha Online - Ciência. Disponível em http://www1.folha.uol.com.br/folha/ciencia/. Acesso dia 30/11/2005.

GCIS Online Information Guide. Disponível em http://www.gulf-coast.com/. Acesso dia 23/02/2007.

Gulf Coast Reconstruction Watch. Disponível em http://southernstudies.org/gulfwatch/. Acesso dia 06/01/2007. 
Harrah's Casino Hotels. Disponível em http://www.harrahs.com/. Acesso dia 02/11/2006.

Hitting the Economy. Disponível em http://www.msnbc.msn.com/. Acesso dia 02/11/2006.

Hurricane Katrina Impact Studies. Disponível em http://www.usgs.gov/. Acesso dia 06/09/2005.

ICS - Instituto de Ciências Sociais da Universidade de Lisboa. Disponível em http://www.ics.ul.pt/, último acesso dia 25/10/2005.

Jornal da Ciência. Disponível em http://www.jornaldaciencia.org.br/. Acesso dia 18/10/2005.

Jornal O Norte Online. Disponível em http://www.jornalonorte.com.br/. Acesso dia 14/09/2005.

KNABB, Richard D., RHOME, Jamie R., and BROWN, Daniel P. Tropical Cyclone Report Hurricane Katrina. National Hurricane Center. Miami, p. 01-15, 2005.

KROMM, Chris e STURGIS, Sue. A New Agenda For The Gulf Coast. Instituto de Estudos do Sul. Durham, 2007.

LEE, Spike. When the Levees Broke, subtitled A Requiem in Four Acts. HBO, Sydney, 2006.

WALKER, Rob. Letters From New Orleans. 2ª edição. Nova Orleans, p. 137, 2005.

MICHAELIS. Guia de Viagem Michelin - Nova Orleans. Melhoramentos. São Paulo, 2005.

NASA - Hurricane Season 2005 Katrina. Disponível em http://www.nasa.gov/. Acesso 14/09/2005.

Newswise ProfNet Wire Education \& Science Impact of Hurricanes KatrinaRita. Disponível em http://www.newswise.com/. Acesso 19/11/2005.

NBC Network. Disponível em http://www.nbc.com/. Acesso 28/03/2007.

NOAA News Online (Story 2496). Disponível em http://www.noaa.gov/. Acesso 25/03/2007.

Report to the Community 2005 - 2006. UJA Federation of New York, p. 10-11, Nova lorque, 2006. 
Save New Orleans East. Disponível em http://www.saveneworleanseast.org/. Acesso dia 17/01/2007.

SAWKAR, Kalidas. Costal Tourism, Environment, and Sustainable Local Develpment. PNAS, p. 81, 2003.

As Diretrizes da Comissão de Assistência ao Desenvolvimento. OECD-OCDE, p. 2, 2002.

SHEIKH, Pervaze A. The Impact of Hurricane Katrina on Biological Resources. Congressional Research Service. 2005.

SPITZER, Nick. Blues for New Orleans: Mardi Gras And America's Creole Soul. University of Pennsylvania Press, Philadelphia, 2006.

STONE, Gregory W. DESIGN, FABRICATION, DEPLOYMENT AND MAINTENANCE OF THE MONITORING SYSTEM. Louisiana State University. Nova Orleans, p. 05-08, 2002.

Sociologia, Problemas e Práticas - COASTAL TOURISM, ENVIRONMENT, AND SUSTAINABLE LOCAL DEVELOPMENT. Disponível em http://www.scielo.oces.mctes.pt/. Acesso 04/11/2005.

SunHerald.com. Disponível em http://www.sunherald.com/. Acesso dia 17/01/2007.

The Bush Administration. Disponível em http://www.whitehouse.org/. Acesso dia 17/01/2007.

The United States Department of Labor Home Page, Secretary of Labor Elaine L_Chao. Disponível em http://www.dol.gov/. Acesso 03/05/2006.

Tropical cyclone - Wikipedia, the free encyclopedia. Disponível em http://pt.wikipedia.org/. Acesso 08/03/2007.

WALKER, Rob. Letters from New Orleans. Garrett County Press. New York, 2005.

WLOX-TV. Disponível em http://www.wlox.com/. Acesso dia 23/02/2007.

World Meteorological Organization. THIRD Tropical Cyclone RSMCs Technical Coordination Meeting. Disponível em http://www.wmo.ch/pages/index_en.html. Acesso em 25/04/2007.

WURMAN, Richard Saul. Access New Orleans. Harpercollins Usa, Houston, 2001. 
ZAGONEL, Rosa Maria. Influência da Cultura de Origem dos Descendentes de Imigrantes Japosenes no Desempenho Acadêmico e no Concurso Vestibular/2000 da UFPR. Universidade Federal do Paraná, p. 32, Curitiba, 2002. 


\section{ANEXOS}

\section{ANEXO A - Imagens ilustrativas}
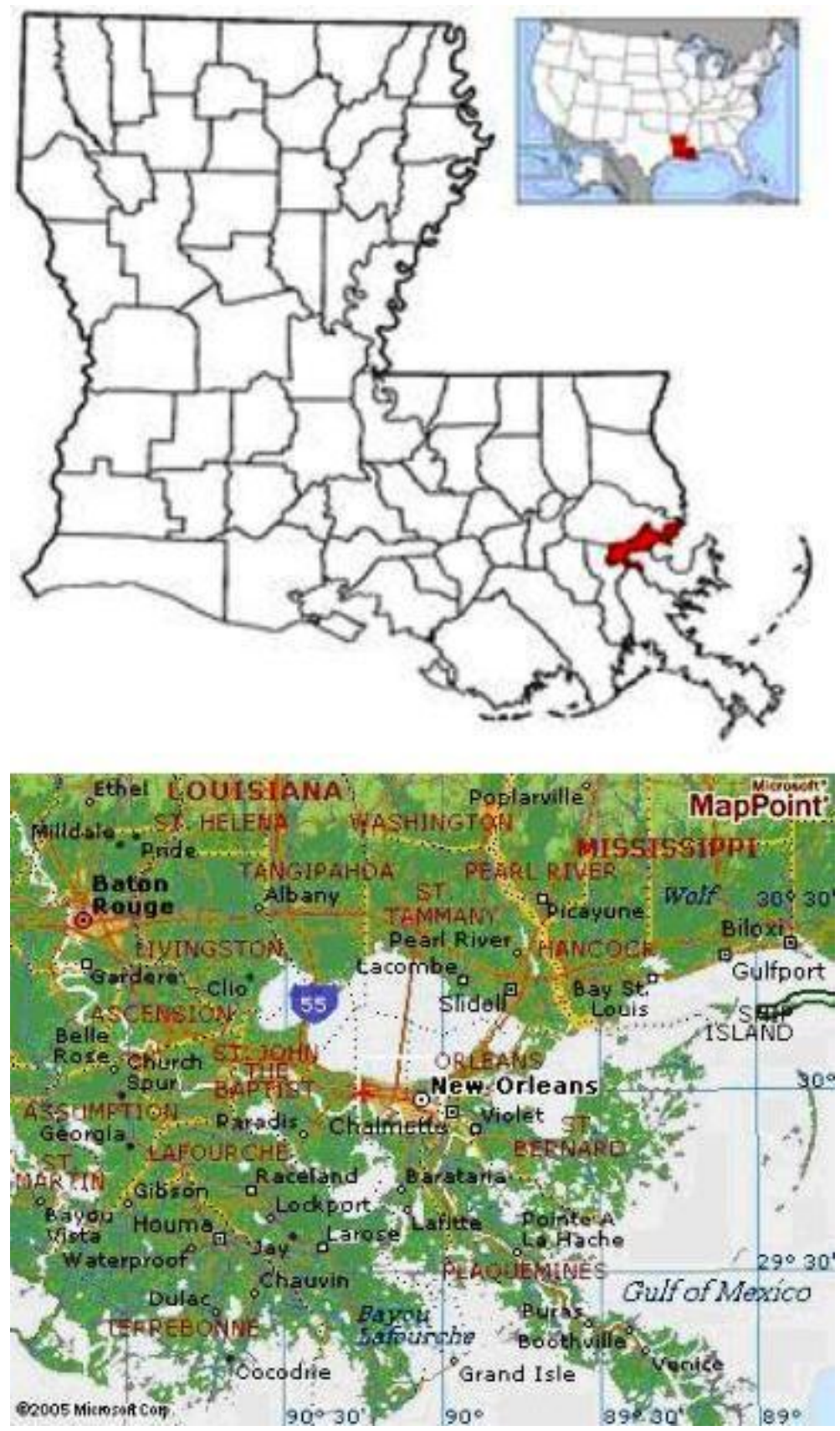

Imagem 1 - Microsoft MapPoint: localização geográfica de Nova Orleans. 


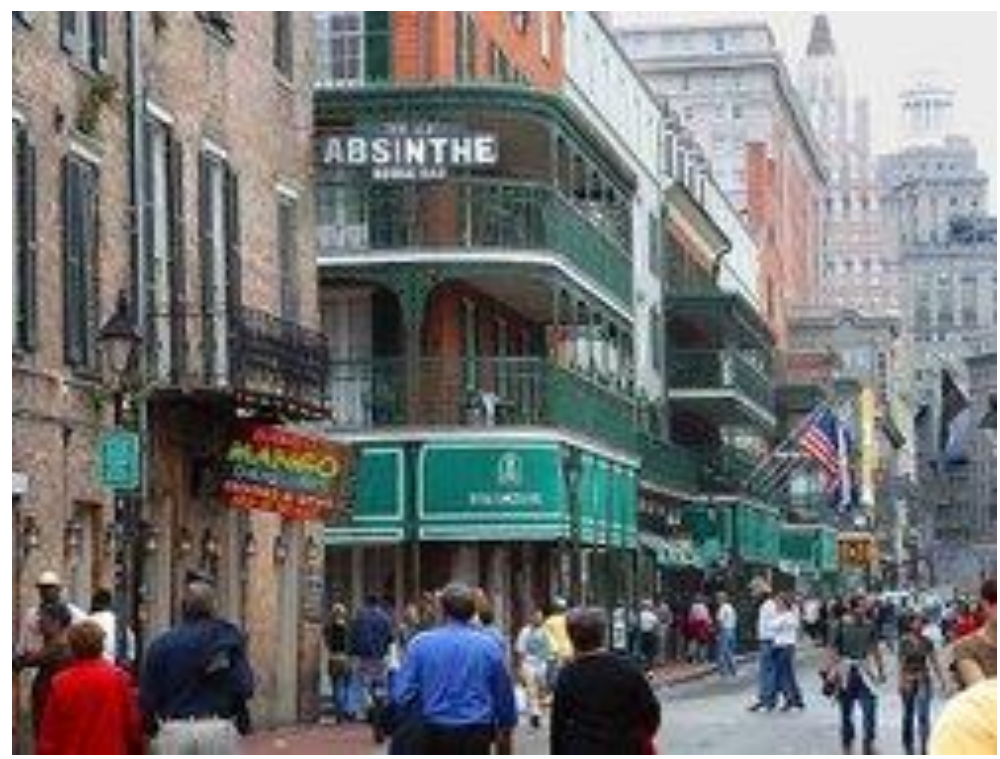

Imagem 2 - Terra Notícias: Bourbon Street, em 2003.

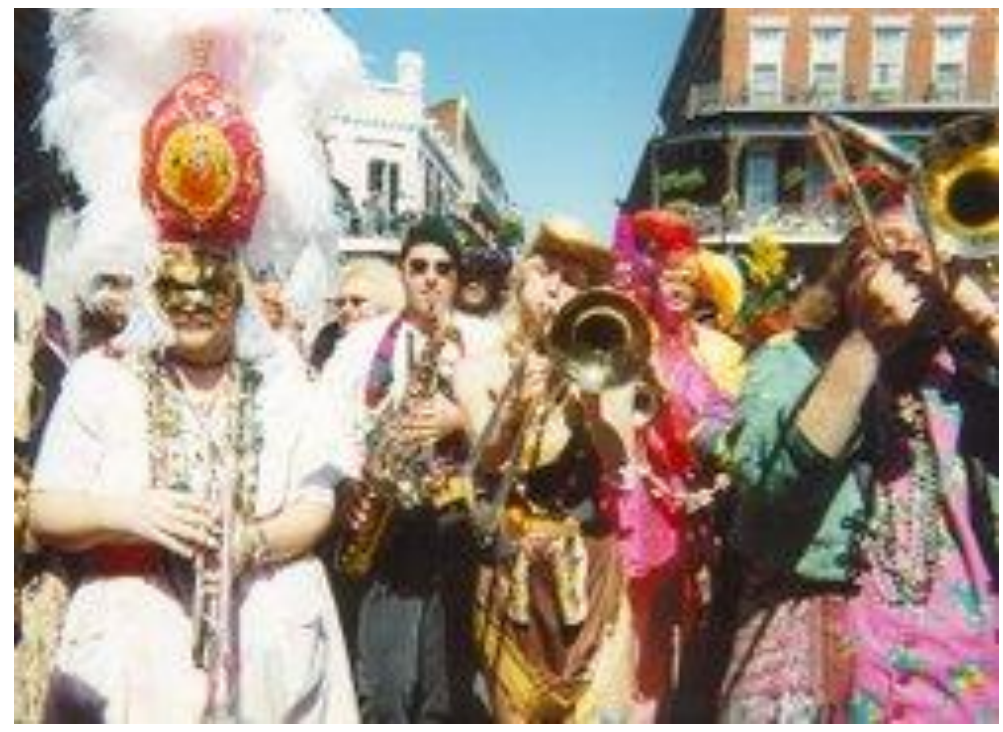

Imagem 3 - Terra Notícias: Mardi Gras. 


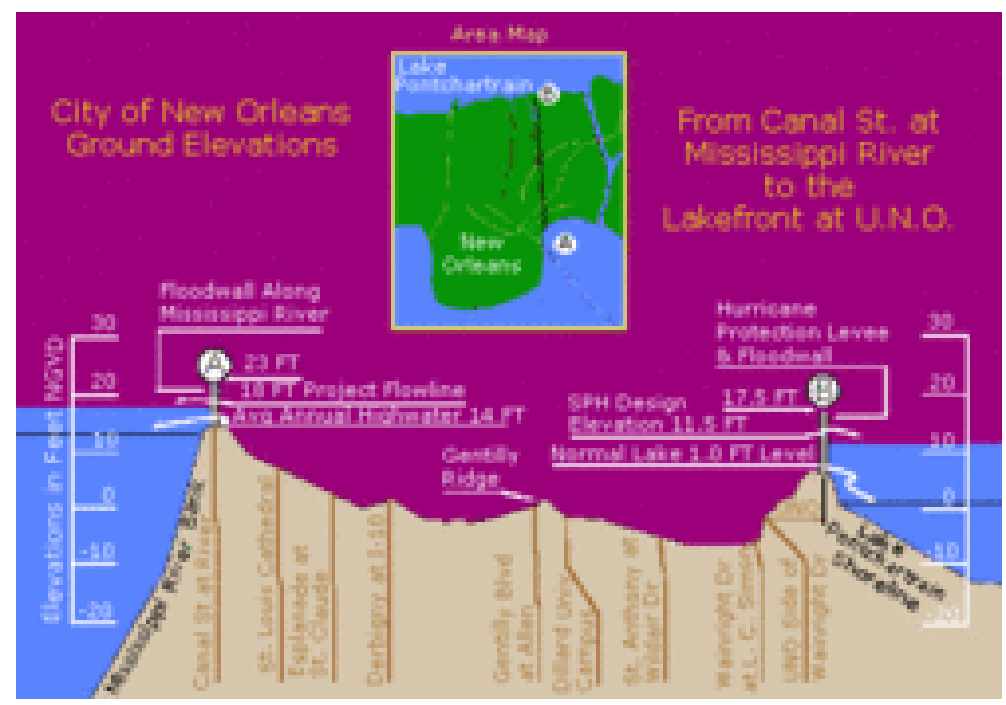

Imagem 4 - Terra Notícias: aspecto topográfico de Nova Orleans.

11:40AM EDT 31-AUG-2005

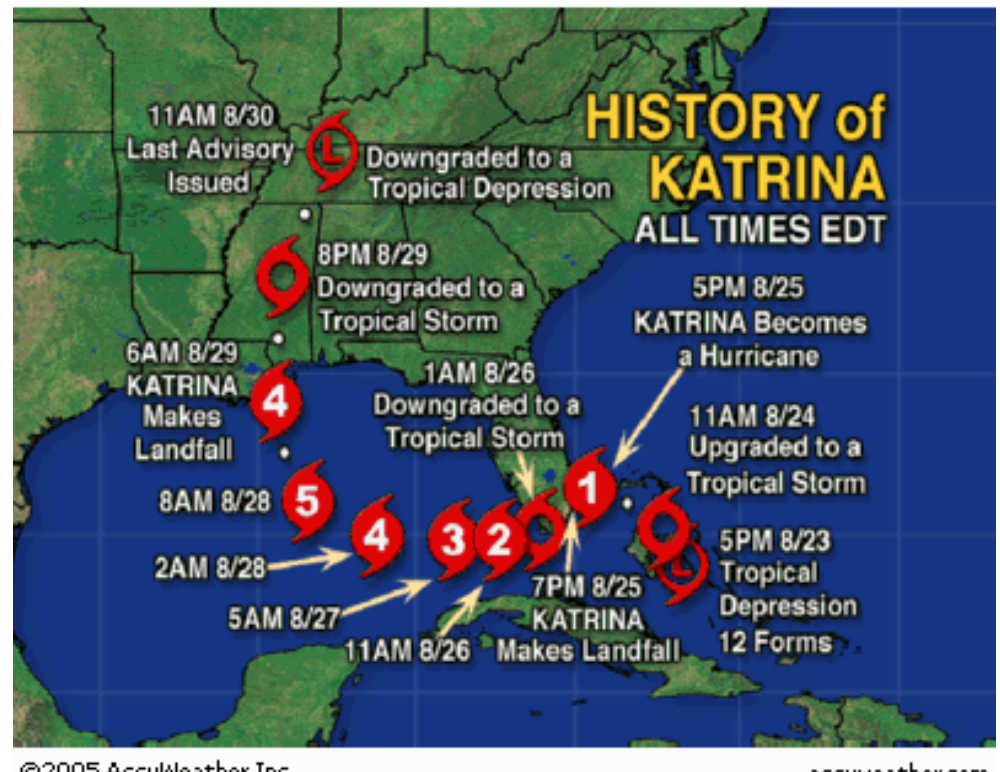

Imagem 5 - AccuWeather: histórico do furacão Katrina. 


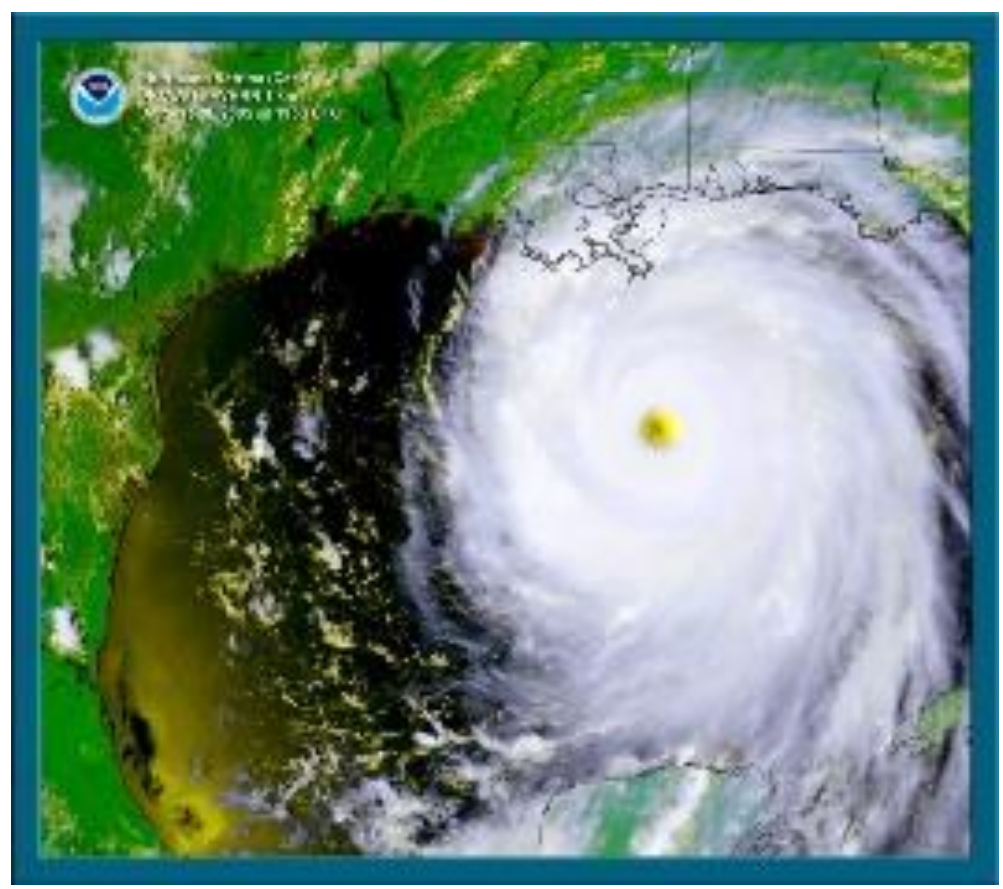

Imagem 6 - NOAA: imagem de satélite do Katrina antes de atingir a região de Nova Orleans.
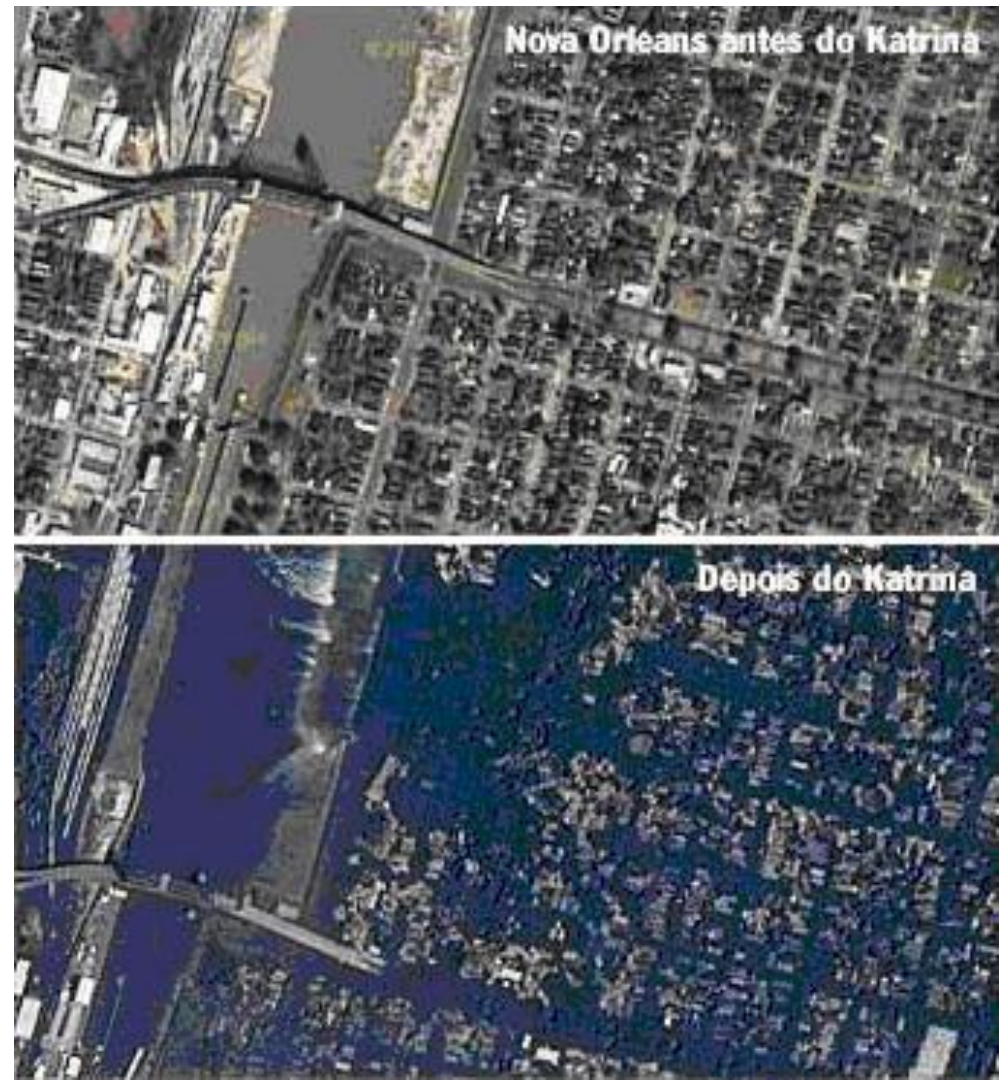

Imagem 7 - Google Maps: Nova Orleans, antes e depois do Katrina. 


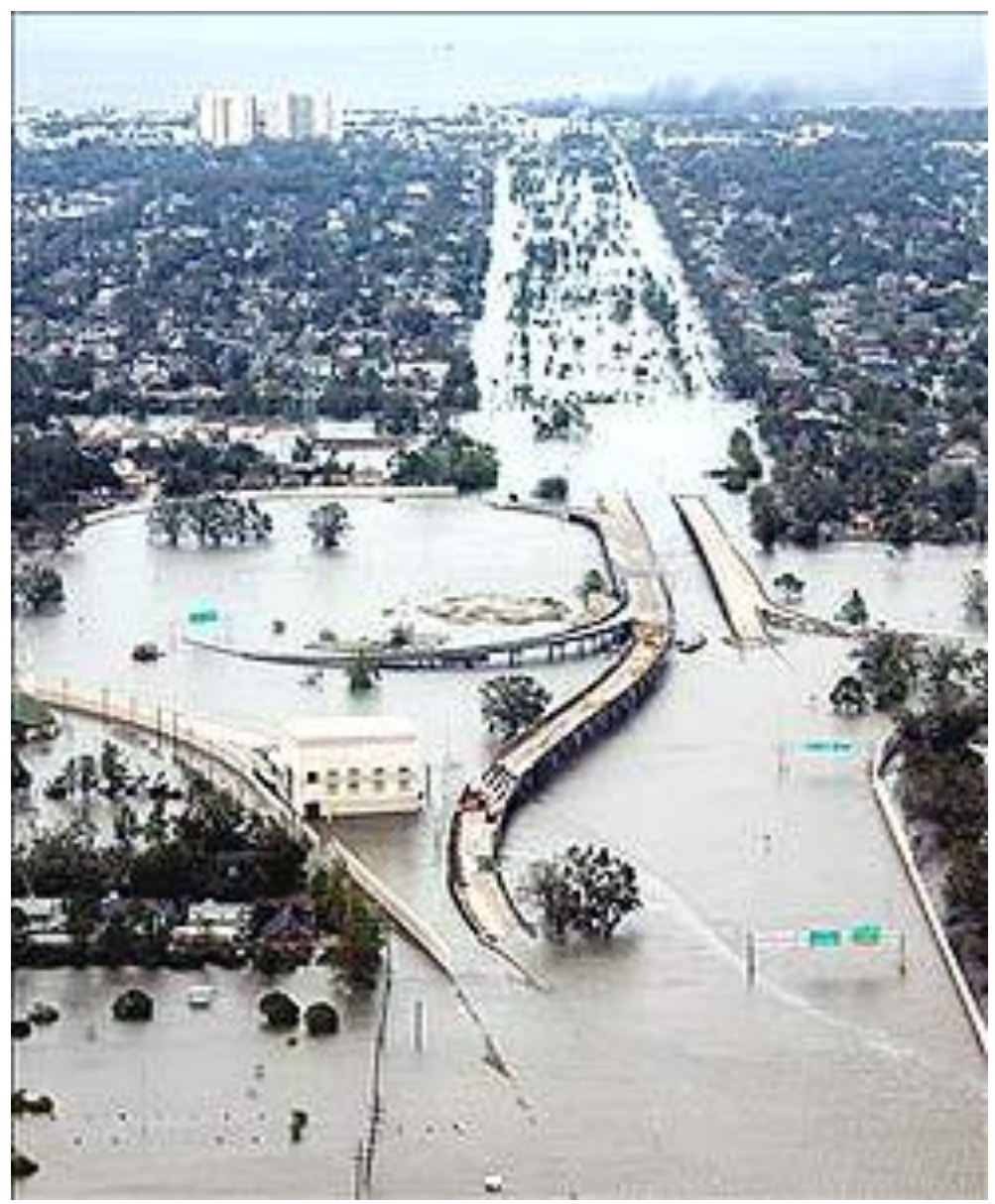

Imagem 8 - Terra Notícias: foto aérea de parte de Nova Orleans alagada.



Imagem 9 - Terra Notícias: primeira missa católica celebrada após o Katrina. 